STRUCTURAL BIOLOGY COMMUNICATIONS

ISSN 2053-230X

Keywords: annotation; online structure visualization; augmented reality; integrated multimedia.

\section{Taking biological structure communications into the third dimension}

\author{
Mark J. van Raaij ${ }^{\mathrm{a} *}$ and Janet Newman ${ }^{\mathrm{b} *}$
}

a Department of Molecular Structure, Centro Nacional de Biotecnología, Consejo Superior de Investigaciones Cientificas, Madrid, E-28049, Spain, and ${ }^{\mathbf{b}}$ Collaborative Crystallisation Centre (C3), CSIRO, 343 Royal Parade, Parkville, VIC 3052, Australia. *Correspondence e-mail: mjvanraaij@cnb.csic.es, janet.newman@csiro.au

In this issue of Acta Crystallographica F, Structural Biology Communications, Firth et al. (2019) present a text-mining tool for automatic protein-residue annotation in published papers. The tool, called pyresid, searches the text of an article for references to amino acids, then identifies the relevant protein and links that amino acid reference in the text to the residue in the associated PDB or mmcif file(s). In doing so, it enables the reader, at the touch of a button, to jump to the relevant part of the $3 \mathrm{D}$ structure.

By the time you read this, our developer, Simon Westrip, will have implemented an annotation system for all our Acta $F$ articles that uses pyresid behind the scenes. For example, if you are reading this online, you can navigate to Mank et al. (2018), 'Structure of aspartate $\beta$-semialdehyde dehydrogenase from Francisella tularensis' or to Molina et al. (2018), 'Structure and stability of the human respiratory syncytial virus M2-1 RNAbinding core domain reveals a compact and cooperative folding unit'. Clicking on one of the highlighted amino acids in these articles will bring up a simple structure browser (based on 3Dmol.js; Rego \& Koes, 2015), showing where the selected residue is in the 3D structure. Using the spanner icon, you can display the protein in cartoon format, stick format or ball-and-stick format. It will also allow you to hide or display water molecules and choose a white or black background. For display of the associated experimental electron density, you will need to open a specialized structure visualization program but this may be included in future versions if the annotations prove popular.

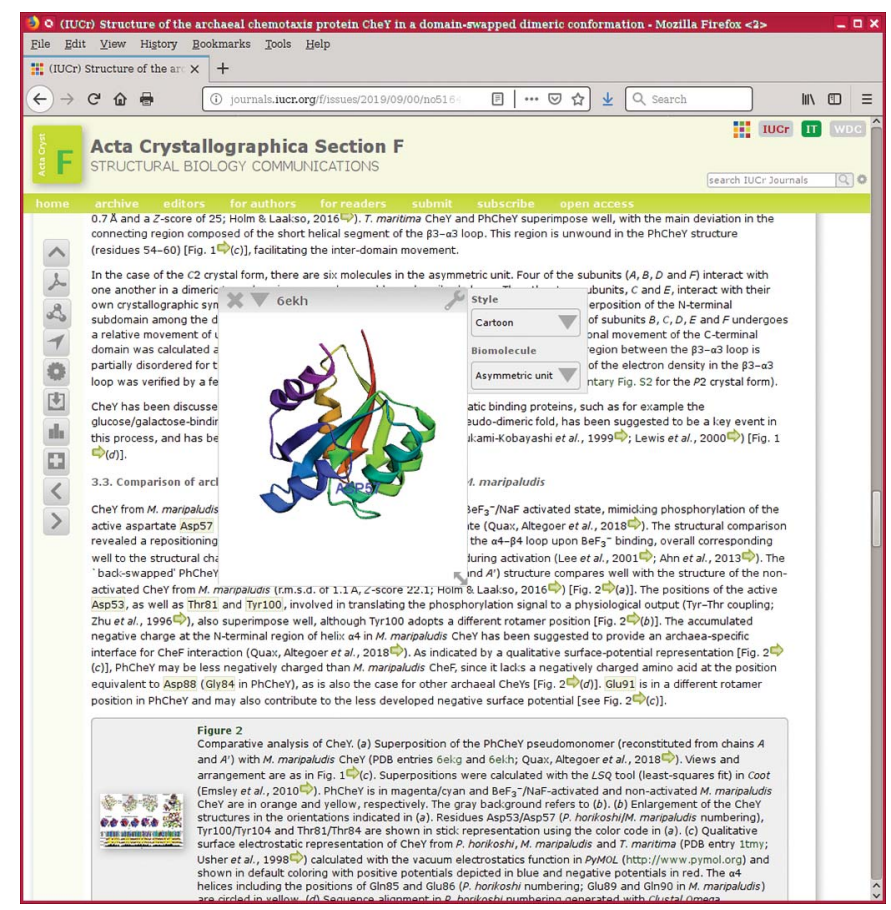

An example of an Acta $F$ article (Paithankar et al., 2019) annotated to show the residue Asp57. 
We think our pyresid implementation is a good example of how integrated multimedia can enhance the reader experience, by enabling the facile location of biologically important amino acid residues in 3D structural models. We have included all Acta $F$ papers to begin with and will extend the implementation to other IUCr journals as appropriate. Together with mobile phone augmented reality apps such as Augment (https://www.augment.com/) and ScholAR (https://www. ini.usc.edu/ScholAR/download.html), reading and, more importantly, understanding structural biology papers has never been easier!

\section{References}

Firth, R., Talo, F., Venkatesan, A., Mukhopadhyay, A., McEntyre, J., Velankar, S. \& Morris, C. (2019). Acta Cryst. F75, 665-672.

Mank, N. J., Pote, S., Majorek, K. A., Arnette, A. K., Klapper, V. G., Hurlburt, B. K. \& Chruszcz, M. (2018). Acta Cryst. F74, 14-22.

Molina, I. G., Josts, I., Almeida Hernandez, Y., Esperante, S., Salgueiro, M., Garcia Alai, M. M., de Prat-Gay, G. \& Tidow, H. (2018). Acta Cryst. F74, 23-30.

Paithankar, K. S., Enderle, M., Wirthensohn, D. C., Miller, A., Schlesner, M., Pfeiffer, F., Rittner, A., Grininger, M. \& Oesterhelt, D. (2019). Acta Cryst. F75, 576-585.

Rego, N. \& Koes, D. (2015). Bioinformatics, 31, 1322-1324. 